\title{
Reference values of alanine transaminase and aspartate transaminase in apparently healthy individuals and their relation with body mass index.
}

\author{
1. MBBS \\ PGR Surgery \\ Aziz Bhatti Teaching Hospital, \\ Gujrat. \\ 2. MBBS \\ House Officer \\ Jinnah Hospital Lahore. \\ 3. MBBS \\ PGR Medicine \\ Mayo Hospital, Lahore. \\ 4. MBBS \\ House Officer Medicine \\ Jinnah Hospital Lahore. \\ 5. MBBS \\ House Officer Medicine \\ Jinnah Hospital Lahore. \\ 6. MBBS \\ King Edward Medical University, \\ Lahore \\ Correspondence Address: \\ Dr. Malik Muhammad Atif \\ House no. 226, Street no. 8, Qasim \\ Town, \\ Near District Police Lines, Bahawalpur. \\ malikmatif@gmail.com \\ Article received on: \\ 12/03/2020 \\ Accepted for publication: \\ 30/05/2020
}

Salman Farooq Dar ${ }^{1}$, Abeera Kali ${ }^{2}$, Malik Muhammad Atif ${ }^{3}$, Saad Javed ${ }^{4}$, Muhammad Burhan Majeed Rana ${ }^{5}$, Umair Haider ${ }^{6}$

ABSTRACT... Objectives: The purpose of this study is to determine the reference values of ALT and AST in healthy, young individuals of Lahore and compare them with international reference values and to determine its relation with Body Mass Index. Study Design: Descriptive Cross Sectional Study. Setting: Department of Pathology, Jinnah Hospital Lahore. Period: March 2017 to May 2017. Material \& Methods: Blood Samples were drawn from apparently healthy volunteers and medical students coming to Blood Bank of Jinnah Hospital, Lahore for blood donation, and their ALT and AST values were obtained after screening. Data was analyzed using SPSS v.20 and values between 5th and 95th percentile of ALT and AST levels from healthy subjects were taken as reference values. Results: Reference values for ALT came out to be 13.50-52.50 IU/I whereas reference values for AST were 15.75-47.00 IU/L. It was also observed that Body Mass Index had direct correlation with upper normal limit of ALT \& AST values. Conclusion: Values of ALT and AST in our study were consistent with the reference values given in the text books.

Key words: $\quad$ Alanine Transaminase, Aspartate Transaminase, BMI and ALT, BMI and AST, Reference Range, Serum Markers, Upper Normal Limit.

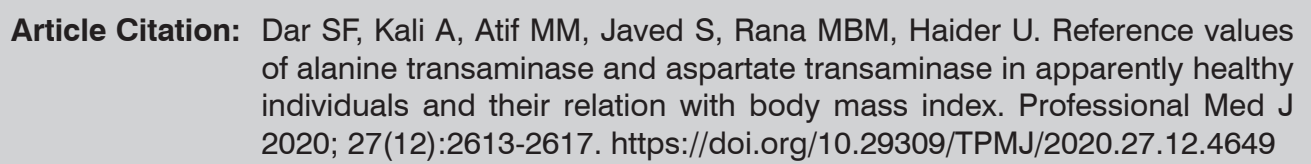

\section{INTRODUCTION}

Alanine Transaminase (ALT) and Aspartate Transaminase (AST) are enzymes that belong to Transferase group of enzymes and catalyze reversible reactions in cytosol and mitochondria respectively. These are present within body cells especially liver cells and are released into serum upon tissue injury. These are the most commonly used indicators of liver function and liver injury. Serum ALT levels are more specific than AST for liver injury. ${ }^{1}$

Numerous studies have revealed different values of ALT and AST reflecting racial and geographical variations. A study conducted at Korea Medical Insurance Corporation in 2004 suggested that the best cut-off values for the prediction of liver diseases in men were $31 \mathrm{IU} / \mathrm{L}$ for aspartate aminotransferase (AST) and 30 IU/L for alanine aminotransferase (ALT). The cut- off value for women couldn't be established but was expected to be lower than men. ${ }^{2}$ An update from Italy on reference range of ALT published in 2002 suggested the upper limit should be set at $30 \mathrm{IU} / \mathrm{L}$ for men and $19 \mathrm{lU} / \mathrm{L}$ for women as compared to currently accepted values of $40 \mathrm{lU} / \mathrm{L}$ and $30 \mathrm{IU} / \mathrm{L}$ respectively. ${ }^{3} \mathrm{~A}$ study done by Piton and colleagues in 1998 recommended normal values of ALT as $31 \mathrm{IU} / \mathrm{L}$ for females with Body Mass Index (BMI) $\leq 23,42 \mathrm{IU} / \mathrm{L}$ for males with BMI $\leq 23,44$ for females with $\mathrm{BMI}>23$, and $66 \mathrm{IU} / \mathrm{L}$ for males with $\mathrm{BMI}>23 .{ }^{4} \mathrm{~A}$ study conducted by Kumar and colleagues in western India in 2013 suggested mean AST levels to be $21.4 \pm 8.7 \mathrm{IU} / \mathrm{L}$ for men and $18 \pm 8.8 \mathrm{IU} / \mathrm{L}$ for women who had normal BMI. Meanwhile, mean ALT levels for individual with $\mathrm{BMI}<23$ were $20.5 \pm 11.8 \mathrm{IU} / \mathrm{L}$ for men and $15.0 \pm 7.8 \mathrm{IU} / \mathrm{L}$ for women. ${ }^{5}$ According to a study done in Taiwan by $\mathrm{Wu}$ and colleagues in 2012, upper 95th percentile of ALT levels in normal 
reference population were $21 \mathrm{IU} / \mathrm{L}$ for men and 17 IU/L for women. ${ }^{6}$ In 2006, Kariv and colleagues estimated levels of ALT in healthy individuals to be $37.5 \mathrm{IU} / \mathrm{L}$, which was lower than the accepted reference level from the test manufacturer which was $52 \mathrm{IU} / \mathrm{L}$. Significant association with glucose, cholesterol and gender was also found. ${ }^{7}$ In 2013, a study done on older individuals ( $>50$ years) by Kabir et al in Iran concluded that upper normal limit of ALT was $21.4 \mathrm{IU} / \mathrm{L}$ in males and $18.8 \mathrm{IU} / \mathrm{L}$ for females which is far lower than the currently accepted reference values. ${ }^{8}$

The upper normal limit of alanine transaminase levels has been challenged recently and a number of studies suggest that reference values need to be set at a lower threshold. To our knowledge, no significant studies have been done to assess the accuracy of reference values of alanine transaminase and aspartate transaminase, being used by different Laboratories in Pakistan. The purpose of this study is to find out the reference values of ALT and AST in healthy and young individuals in Lahore and compare them with international reference values (10-50 IU/L for ALT and $10-45 \mathrm{IU} / \mathrm{L}$ for AST) ${ }^{9}$ and values provided by other studies. This study also aims to determine the relationship of Body Mass Index (BMI) with ALT \& AST values.

\section{MATERIAL \& METHODS}

A prospective cross-sectional study was carried out under the supervision of Pathology department of Jinnah Hospital, Lahore (JHL) over a period of 3 months (March 2017 to May 2017) after approval of study synopsis from Institutional Ethical Review Board. The study was done in association with blood bank and clinical biochemistry laboratory which is the part of Pathology department, JHL. Purposive sampling was done. The study population consisted of voluntary blood donors and medical students coming to blood bank of JHL for blood donation.

Individuals aged 18-35, negatively screened for Hepatitis B \& C and HIV, having BMI 18-23 kg/ m2, with stable vital signs (pulse between 60-100/ min, blood pressure systolic $100-160 \mathrm{~mm}$ of $\mathrm{Hg}$, diastolic $60-90 \mathrm{~mm}$ of $\mathrm{Hg}$, temperature $\leq 98.6 \mathrm{~F}$ and respiratory rate $12-20)$ were included in the study.

Individuals having history of jaundice, those diagnosed with Liver disease, diabetes mellitus, hypertension or bleeding /coagulation disorders, known cases of chronic cardiac, renal, musculoskeletal or central nervous system disorders, individuals who have taken potentially hepatotoxic drugs within last one month, alcoholics with intake of $>20 \mathrm{~g} /$ day or any illicit drug abuse, and those who came out to be seropositive for hepatitis B surface antigen, anti HCV antibody, HIV 1 and 2, VDRL and malarial parasite were excluded from the study.

After taking informed consent, willing subjects' health status was properly evaluated by a closed-ended questionnaire under supervision of the research team members. Confidentiality of the personal information of the participants was observed. Anthropometric measurements were taken that included Height in centimeters using stadiometer; weight in kilograms using standardized weighing machine.

Blood samples were drawn from each subject. Every sample was split into two; one for screening in plain test tube and the other for measuring ALT \& AST levels in serum vials. Screening for Hepatitis B Surface Antigen (HBsAg), Hepatitis C Virus (HCV), Human Immunodeficiency Virus (HIV), Venereal Disease Research Labs (VDRL) and Malarial parasite was done using standard diagnostic kits (HBsAg kit and HCV kit manufactured by accurate, HIV kit manufactured by accuCheck). ALT and AST levels were measured using Erma inc. biochemical analyzer model AE600N using reagents manufactured by HUMAN. Analyzers were standardized using quality control sample Humantrol-N (manufactured by HUMAN).

All the collected data was analyzed using SPSS v.20. Alanine Transaminase and Aspartate Transaminase levels were charted against variables i.e. Age, Sex and BMI. The values between 5th and 95th percentile of ALT and AST levels collected from healthy subjects were taken as reference values. 


\section{RESULTS}

A total of 242 samples were collected from voluntary donors, out of which, 238 (98.3\%) were males while $4(1.7 \%)$ were females. Samples with positive serological results were not included in the study. Mean age was $25.87 \pm 4.83$ years (range 18-43 years) for overall sample. Mean BMI was $24.92 \pm 3.30$ (range 17.70-36.70). We called it Sample A. This sample was analyzed and samples were excluded on the basis of exclusion and inclusion criteria to get "ideal population" giving rise to Sample B of 74 individuals which included 70 males (94.6\%) and 4 females (5.4\%). Mean age was 24.51 \pm 3.97 years (range 18-35 years) and mean BMI was 21.33 \pm 1.24 (range 18.90-23.00).

The rest of the sample that was excluded from ideal population comprised Sample C which included 168 males only with mean age of $26.5 \pm 5.06$ years (range 18-43 years) and mean
BMl of $26.56 \pm 2.53$ (range 23.10-36.70).

In Sample A, mean values for ALT came up to be; 17.00-62.00 IU/I while mean values for AST were; 16.00-51.70 IU/L (shown in Table-I).

In Sample B, mean values of ALT came out to be 13.50-52.50 IU/I while mean values of AST were 15.75-47.00 IU/L (shown in Table-II).

In Sample B, mean values of ALT came out to be 13.50-52.50 IU/I while mean values of AST were 15.75-47.00 IU/L (shown in Table-II).

On the other hand, mean values of ALT were 18.00-66.60 IU/I and those for AST were 16.00$56.80 \mathrm{IU} / \mathrm{L}$ in Sample C.

The linear curves in Figures-1 and 2 show relationship of BMI with ALT and AST values in Sample A.

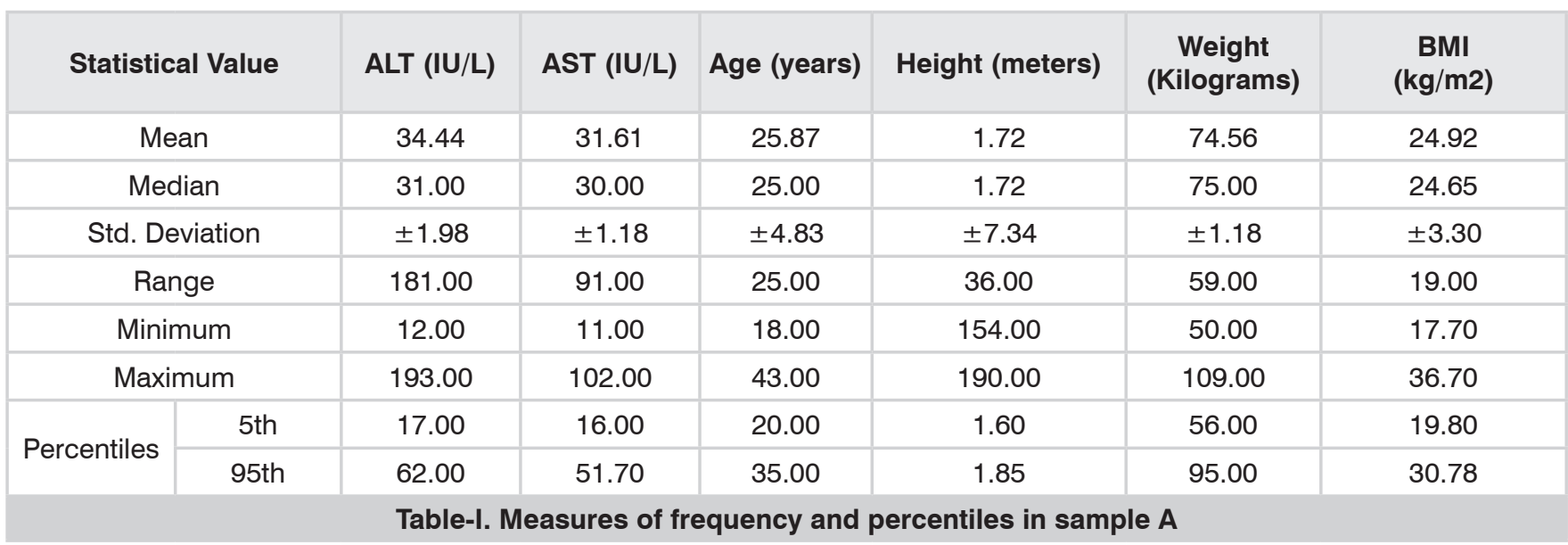

\begin{tabular}{|c|c|c|c|c|c|c|c|}
\hline \multicolumn{2}{|c|}{ Statistics } & ALT (IU/L) & AST (IU/L) & Age (years) & Height (meters) & $\begin{array}{c}\text { Weight } \\
\text { (kilograms) }\end{array}$ & $\begin{array}{c}\text { BMI } \\
(\mathrm{kg} / \mathrm{m} 2)\end{array}$ \\
\hline \multicolumn{2}{|c|}{ Mean } & 29.74 & 29.40 & 24.51 & 1.71 & 63.54 & 21.33 \\
\hline \multicolumn{2}{|c|}{ Median } & 29.00 & 29.00 & 24.00 & 1.72 & 63.00 & 21.50 \\
\hline \multicolumn{2}{|c|}{ Std. Deviation } & \pm 1.09 & \pm 9.66 & \pm 3.97 & \pm 7.13 & \pm 7.36 & \pm 1.24 \\
\hline \multicolumn{2}{|c|}{ Range } & 53.00 & 59.00 & 17.00 & 30.00 & 37.00 & 4.10 \\
\hline \multicolumn{2}{|c|}{ Minimum } & 12.00 & 11.00 & 18.00 & 156.00 & 50.00 & 18.90 \\
\hline \multicolumn{2}{|c|}{ Maximum } & 65.00 & 70.00 & 35.00 & 186.00 & 87.00 & 23.00 \\
\hline \multirow{2}{*}{ Percentiles } & 5th & 13.50 & 15.75 & 19.00 & 1.60 & 53.00 & 18.97 \\
\hline & 95th & 52.50 & 47.00 & 32.25 & 1.84 & 78.00 & 23.00 \\
\hline
\end{tabular}


ALT

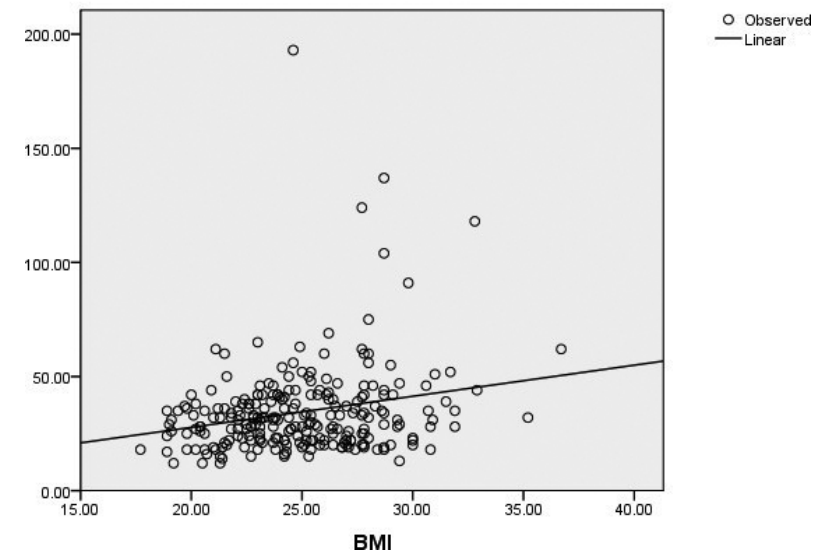

Figure-1. Linear curve estimation showing change in ALT levels with BMI in sample A. (UNIT = IU/L) (BMI IN kg/m2)

\section{DISCUSSION}

Our study included a total of 238 males, 17 of which were obese $(\mathrm{BMI}>30.0)$ while 99 were over-weight (BMI 25.0-29.9) according to WHO criteria. ${ }^{10}$ One of our objectives was to correlate BMI with ALT and AST values because increased BMI (obesity) has been known to cause metabolic syndrome and fatty liver disease, and is also an independent risk factor for Cardiovascular Diseases. ${ }^{11}$

When correlation of ALT and AST with BMI and age was tested on Sample A, it appeared to be a significant positive correlation between $\mathrm{BMI}$ and ALT ( $P$ value $<0.05$, Pearson correlation +0.227 ) shown in Figure $\mathrm{I}$.

There was also a significant positive correlation between BMI and AST ( $P$ value $<0.05$, Pearson correlation +0.135) as shown in Figure II. The correlation between age and serum transaminases was positive for ALT and negative for AST but both were not significant ( $P$ value $<0.05)$.

None of the correlation between BMI, age and transaminases was significant in sample $B$ and sample $C$ except positive correlation between $B M I$ and ALT in sample C (P value 0.05 , Pearson correlation +0.152 ). This was consistent with the study of Piton et al. which showed similar positive correlation between BMI and ALT.

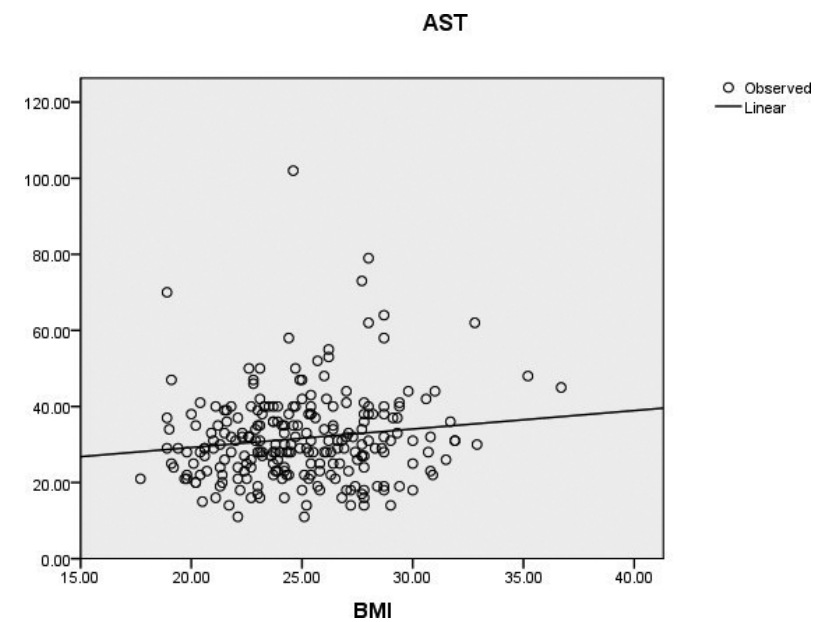

Figure-2. Linear curve estimation showing change in AST levels with BMI in sample A (UNIT = IU/L) (BMI IN kg/m2)

When comparing the reference range with other studies, it was observed that values in our study were found to be higher than other studies 3,4,6 and were closer to the values taken from a text book (ALT 10-50, AST 10-47). ${ }^{9}$

One limitation of our study was the limited sample size as compared to other larger studies conducted in other centers. Moreover, due to lack of female volunteers, the values obtained in our study might not reflect the actual reference ranges in female population of the country. A number of individual with sub-clinical liver disease could have gone un-diagnosed which could have been prevented by use of multiple readings of serum transaminases and use of other modalities like ultrasound liver and liver biopsy but using these techniques was beyond the scope of this study.

\section{CONCLUSION}

Values of ALT and AST in apparently healthy individuals appear to be consistent with the reference values already in use internationally and suggested by other studies. Also there appears to be a significant positive correlation between $\mathrm{BMI}$ and upper normal limit of ALT \& AST values.

\section{CONFLICT OF INTEREST}

The authors whose names are listed above certify that they have NO affiliations with or involvement 
in any organization or entity with any financial interest (such as honoraria; educational grants; participation in speakers' bureaus; membership, employment, consultancies, stock ownership, or other equity interest; and expert testimony or patent-licensing arrangements), or non-financial interest (such as personal or professional relationships, affiliations, knowledge or beliefs) in the subject matter or materials discussed in this manuscript.

Copyright@ 30 May, 2020.

\section{REFERENCES}

1. Mosby's Medical Dictionary, 9th edition. (C) 2009, Elsevier.

2. Hyeon CK, Chung MN, Sun HJ, Kwang HH, Oh DK, Suh LL. Normal serum aminotransferase concentration and risk of mortality from liver diseases: Prospective cohort study. BMJ 2004 [2016 Sep 16]; 328:983. Available from; URL: http://www.bmj.com/ content $/ 328 / 7446 / 983$ ? variant $=$ full-text $\&$ tab $=$ responseform.

3. Prati D, Taioli E, Zanella A, Torre ED, Butelli S, Vecchio ED, et al. Updated definitions of healthy ranges for serum alanine aminotransferase level. Annals of internal medicine. 2002 July 2 [2016 Sep 17]; 137(1): Available at: http://annals.org/article.aspx?articleid $=715360$.

4. Piton A, Poynard T, Bismut FI, Khalil L, Delattre J, Pelissier E. Factors associated with serum alanine transaminase activity in healthy subjects: Consequences for the definition of normal values, for selection of blood donors, and for patients with chronic Hepatitis C. Hepatology. May 1998[2016 Sep 20]; 27(5):1213-1219. Available at: http://onlinelibrary. wiley.com/doi/10.1002/hep.510270505/epdf.
5. Kumar S, Amarapurkar A, Amarapurkar D. Serum aminotransferase levels in healthy population from western India. Indian J Med. December 2013; 138(6):894-899.

6. Wu WC, Wu CY, Wang YJ, Hung $\mathrm{HH}$, Yang HI, Kao $W Y$, et al. Updated thresholds for serum alanine aminotransferase level in a large-scale population study composed of 34346 subjects. Alimentary pharmacology and therapeutics. 2012 July [Updated 2012 September]; 36(6):560-568. Available at: http://onlinelibrary.wiley.com/doi/10.1111/j.13652036.2012.05224.x/full\#publication-history.

7. KarivR, Leshno M, Beth-OrA, Strul H, Blendis L, KokiaE, et al. Re-evaluation of serum alanine aminotransferase upper normal limit and its modulating factors in a large-scale population study. Liver international. 2006 April 10; 26(4):445-450. Available at: http://onlinelibrary. wiley.com/doi/10.1111/j.1478- 3231.2006.01197.x/full.

8. Kabir A, Pourshams A, Khoshnia M, Malekzadeh F. Normal limit for serum alanine aminotransferase level and distribution of metabolic factors in old population of Kalaleh, Iran. Hepatology monthly. 2013 October 20; 13(10):e10640.

9. Colledge NR, Walker BR, Ralston S, Davidson S. Davidson $\mathbf{s}$ principles and practice of medicine. Churchill Livingstone/Elsevier,; 2010.

10. World Health Organization. Obesity: Preventing and managing the global epidemic. Report of a WHO consultation presented at: the World Health Organization; June 3-5, 1997; Geneva, Switzerland. Publication WHO/NUT/NCD/98.1.http://www.who.int/ diabetes/country-profiles/pak_en.pdf?ua=1.

11. Charbek E, Christensen B. Normal vital signs. Medscape, Aug. 2015. Available at: http://emedicine. medscape.com/article/2172054-overview.

\begin{tabular}{|c|l|l|l|}
\hline \multicolumn{3}{|c}{ AUTHORSHIP AND CONTRIBUTION DECLARATION } \\
\hline Sr. \# & \multicolumn{1}{|c|}{ Author(s) Full Name } & \multicolumn{1}{|c|}{ Contribution to the paper } & Author(s) Signature \\
\hline 1 & Salman Farooq Dar & 1 st Author & \\
\hline 2 & Abeera Kali & Author & \\
\hline 3 & Malik Muhammad Atif & Author & \\
\hline 5 & Saad Javed & Author & \\
6 & Umair Haider & Author & \\
\hline
\end{tabular}

